\title{
Occupational contact dermatitis to nickel: experience of the British dermatologists (EPIDERM) and occupational physicians (OPRA) surveillance schemes
}

\author{
K W Shum, J D Meyer, Y Chen, N Cherry, D J Gawkrodger
}

Occup Environ Med 2003;60:954-957

See end of article for authors' affiliations

Correspondence to:

Correspondence to:
Dr D J Gawkrodger, EPIDERM, Centre for Occupational and Environmental Health University of Manchester, Humanities Building, Manchester M13 9PL, UK; D.J.Gawkrodger@ Sheffield.ac.uk

Accepted 30 May 2003

\begin{abstract}
Aims: To examine, from occupational surveillance reporting data, whether scheme reporters considered nickel exposure to play a role in occupational contact dermatitis (OCD) in the UK.

Methods: Data on occupational skin disease in the UK are collected by two occupational disease surveillance schemes, EPIDERM and OPRA. Cases of OCD believed to have relevant nickel exposure reported to EPIDERM or OPRA from February 1993 to January 1999 were studied.

Results: An estimate of 1190 cases of occupational contact dermatitis thought to have relevant nickel exposure (12\% of total estimated OCD) was derived from reports by dermatologists, an average of 198 per year. The highest incidence rates were seen in hairdressers (23.9/100 000 workers/year), bar staff (4.7), chefs and cooks (4.4), retail cash and checkout operators (2.8), and catering assistants (2.5). From May 1994 to January 1999, 158 cases of nickel associated dermatitis (1.9\% of total OCD cases) were estimated; the most frequently reported occupations were electronic assemblers, nurses, sales assistants, and general assemblers. From July 1997 to January 1999, 547 positive patch tests to nickel were reported; in 195 cases $(36 \%)$, nickel was felt to be a relevant occupational allergen (for example, coin handling). In hairdressers, nurses, cooks, and beauticians, nickel was usually considered, if relevant at all, to be only one of several causes of dermatitis.

Conclusions: Up to $12 \%$ of total estimated cases of OCD were thought to be due in part to nickel. Results suggest that nickel hypersensitivity is one of several contributors to $O C D$ in subjects with multiple occupational exposures. Coin handling may be a source of $O C D$ to nickel.
\end{abstract}

$\mathrm{S}$ kin disorders, mainly contact dermatitis, ${ }^{1}$ account for a substantial proportion of occupational disease, nearly one fifth in some surveillance studies. ${ }^{12}$ Nickel is potentially an important occupational allergen and in one series was thought to contribute to $31 \%$ of cases of occupational allergic contact dermatitis. ${ }^{3}$ Nickel has been regarded as the predominant occupational allergen in women and the eighth most common in men. ${ }^{4}$ Occupations commonly linked with nickel associated dermatitis include nickel plating, ${ }^{5}$ electroforming, ${ }^{6}$ hard metal work ${ }^{7}$ and decorating and enamelling in the ceramics industry. ${ }^{8}$ Cleaners, ${ }^{9-11}$ nurses, ${ }^{11}$ caterers, ${ }^{12}$ hairdressers, ${ }^{13}$ and cashiers ${ }^{14}$ are potentially at risk, but the relevance of occupational nickel exposure to the causation of contact dermatitis in these occupations is often questioned. ${ }^{15}$

National surveillance schemes for the reporting of occupational diseases in the UK have been active since 1989. Together these form the Occupational Disease Intelligence Network (ODIN), of which two component schemes, EPIDERM and OPRA (Occupational Physicians Reporting Activity), contribute to the reporting of occupational skin diseases. ${ }^{16}{ }^{17}$ The aims of this study were to examine from occupational surveillance reporting data whether EPIDERM and OPRA scheme reporters considered nickel exposure to play a role in occupational contact dermatitis in the UK for cases reported between 1993 and 1999.

\section{METHODS}

Methods for the surveillance of occupational skin disease have been described previously. ${ }^{17}$ In February 1994, all British consultant dermatologists, then numbering 244, reported incident cases of occupational skin disease to the EPIDERM surveillance scheme at the University of Manchester. The scheme was redesigned in January 1996, so that a "core group", currently comprising 24 dermatologists with a special interest in occupational skin disease reported monthly, with the remaining "sample group" of all other UK dermatology consultants reporting cases seen during a specified calendar month of the year. The estimated yearly rate for the whole sample group was calculated by applying a multiplier of 12 to the reports obtained by monthly sampling. This figure was combined with the cases that had been reported monthly by the core physicians over the 12 month period in order to give estimated yearly figures for the whole group. ${ }^{17}$ Potentially, the whole population of the UK covered by the NHS, is included.

Participating dermatologists complete a reporting card for the month(s) in question, even if they had not seen a case of occupationally related illness during that month. Late responders were reminded by telephone or fax. On the reporting card, information was requested on seven categories of occupational skin disease. Details requested on each case included initials, sex, date of birth, abbreviated postcode, job, industry, and suspected agent(s). Patch tests in participating centres were performed in a standardised way, ${ }^{18}$ with a standard series including nickel. ${ }^{18}$ An allergen giving a positive allergic patch test was included if judged to be relevant occupationally in that particular case, as would be the case if there was known and more than transitory occupational contact with that substance. The British Association of Dermatologists has given some guidance on assessing relevancy. ${ }^{18}$

From July 1997 onwards, in order to better understand the possible occupational role of nickel, dermatologists were asked to indicate all positive patch tests to nickel in all cases of occupational contact dermatitis (OCD) reported, and to 


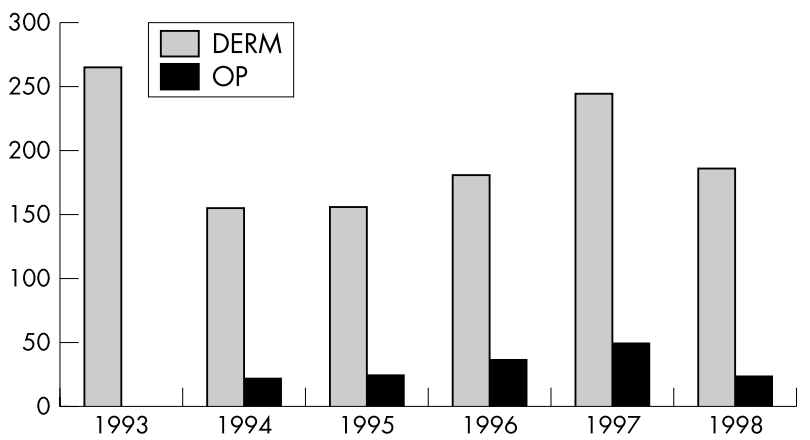

Figure 1 Occupational contact dermatitis attributed to nickel. Yearly estimated numbers of cases from dermatologists (DERM) and from occupational physicians (OP) by year. (For 1994, figures from occupational physicians include only cases from May, when reporting began, to January.)

indicate whether or not nickel was believed to be of any relevance to the causation of the OCD.

Occupational physicians in the UK were included in the surveillance scheme from May 1994, and for the first 17 months reported every new case of occupational skin disease. In January 1996, OPRA was initiated and, from that point, medical inspectors from the Health and Safety Executive (currently numbering 18) reported cases monthly, while the other occupational physicians (currently numbering 772) only reported cases seen during one of 12 specified calendar months of the year. ${ }^{17}$ The OPRA reporting card includes the category "contact dermatitis", and occupational physicians are asked to list suspected agents, in the vast majority of cases without support from patch tests. Annual totals were estimated as in EPIDERM. In each scheme, duplicate reports were identified and eliminated by searching the database for initials, date of birth, and postcode, so no case was counted twice. For calculation of rates, denominators were obtained from the Labour Force Survey. ${ }^{19}$ Because of the start date in February 1993, all surveillance dates shown by calendar year (for example, 1993) cover the 12 months from 1 February in that year to 31 January in the following year.

\section{RESULTS}

From February 1993 to January 1999, an estimated 12574 cases of occupational skin disease were reported by dermatologists
(EPIDERM), of which 9937 (79\%) were OCD. In 1190 cases ( $12 \%$ of OCD reported), nickel was one of the suspect agents (mean 198 cases/year; 912 females, 278 males; F:M ratio 3.3:1). Occupational physicians reported an estimate of 10136 new cases of occupational skin disease in the period May 1994 to January 1999 (OPRA). Of these, 8129 were OCD $(80 \%)$, of which $157(1.9 \%)$ were thought to be due at least in part to nickel (mean 33/year; 107 females, 50 males; F:M ratio 2.1:1). There are yearly fluctuations in period prevalences, but there is no consistent trend with time (fig 1). The frequency of occupational nickel dermatitis for women decreased with age, with the highest rates seen in the 16-30 year age group in both schemes (fig 2). There was no age pattern for men, although a slight increase is seen with increasing age in dermatologists' reports.

The occupations most frequently reported by dermatologists (EPIDERM) as believed to show an association between nickel exposure at work and OCD are hairdressers, cleaners, and cooks, with the highest rates (based on numbers employed in the occupation) in hairdressers, bar staff, and cooks (table 1). Occupational physicians (OPRA) report the most frequent occupations to be electronic assemblers (24 cases), nurses (16), sales assistants (14), and general assemblers (12). Most cases reported by dermatologists were viewed as allergic contact dermatitis ( $62 \%$ of cases) or mixed allergic and irritant dermatitis (26\%), with $7 \%$ regarded as primarily an irritant contact dermatitis (nickel contact allergy playing a secondary role) and 5\% not specified.

From July 1997 to January 1999, dermatologists (EPIDERM) reported 547 patients (436 females, 111 males) with patch tests positive for nickel, of which 195 (36\%) were thought to have nickel dermatitis arising from, or made worse by, work. Among women, hairdressers had the highest number of allergic positive patch tests to nickel but, in all except two cases, this was only one of several agents reported, and nickel was felt to be relevant (in terms of occupational exposure being likely and sufficient) in only $19 \%$ (table 2). In the small number of subjects whose occupations involved handling coins and who were reported to have occupational dermatitis, nickel was often reported to be the sole agent.

\section{DISCUSSION}

This report from the EPIDERM and OPRA surveillance schemes provides the national data from the UK on cases

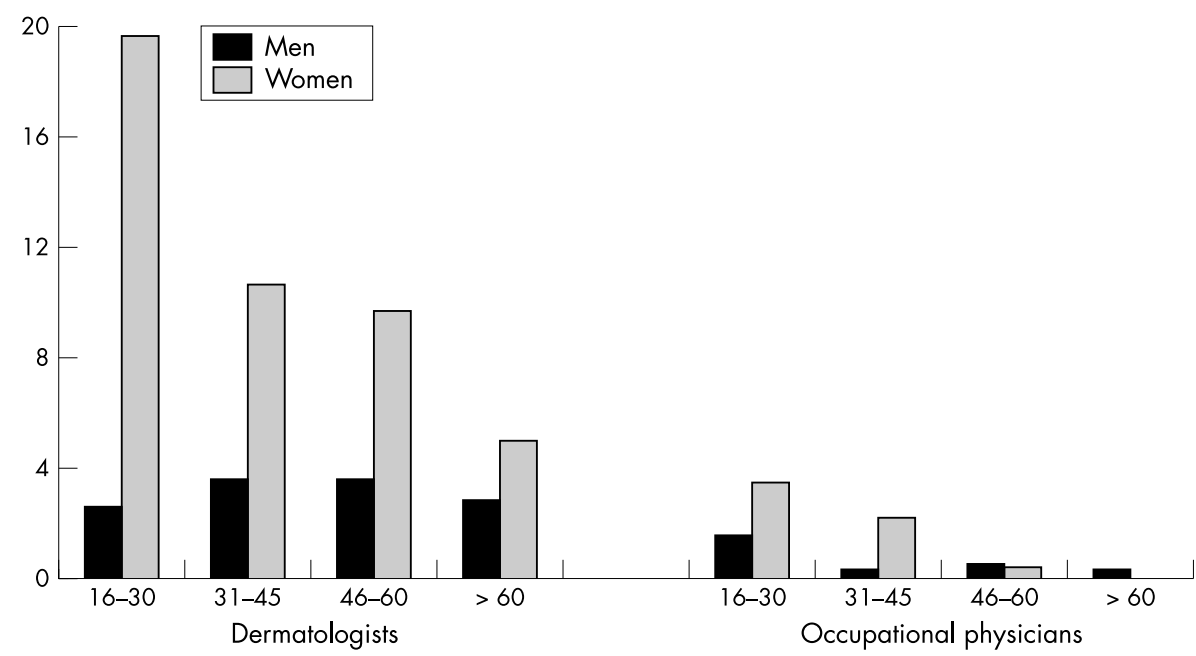

Figure 2 Rates of occupational contact dermatitis attributed to nickel by age and sex, per million employed per year. Estimates from dermatologists (EPIDERM: Feb 1993-Jan 1999) and occupational physicians (OPRA: May 1994-Jan 1999). 
Table 1 Contact dermatitis attributable to nickel

\begin{tabular}{lcc}
\hline Occupation (SOC) & $\begin{array}{l}\text { Estimated } \\
\text { cases }\end{array}$ & $\begin{array}{l}\text { Rate/100 000/ } \\
\text { annum }\end{array}$ \\
\hline Hairdressers (660) & 172 & 23.9 \\
Bar staff (662) & 52 & 4.7 \\
Chefs/cooks (620) & 68 & 4.4 \\
Retail cash \& checkout operators & 38 & 2.8 \\
(721) & 32 & 2.5 \\
Catering assistants (953) & 43 & 2.2 \\
Counter clerks/cashiers (411) & 83 & 1.8 \\
Cleaners (958) & 52 & 1.7 \\
Nurses (340) & 39 & 1.7 \\
Metal workers (516) & 57 & 0.8 \\
Sales assistants (720) & 26 & 0.8 \\
Secretaries (459) & & \\
Overall & 1190 & 0.8 \\
\hline
\end{tabular}

Most frequently reported occupations from dermatologists (EPIDERM), Feb 1993-Jan 1999. Occupational rates using 1997 Labour Force Survey data ${ }^{19}$ as denominator.

SOC, Standard Occupational Classification. ${ }^{20}$

of occupational dermatitis that were believed to be associated with exposure to nickel. In most epidemiological surveillance schemes, except the information network of departments of dermatology (IVDK) in Germany, ${ }^{21}$ there is some form of estimation from sample groups and our data are therefore comparable with those collected in other countries. OCD associated with nickel exposure accounted for $12 \%$ of cases reported by dermatologists, but only $2 \%$ of cases reported by occupational physicians. This difference may reflect the different population presenting to the two specialties. Those working in smaller or poorly regulated industries often have no access to an occupational health service and present instead to general practitioners and then to dermatologists. In addition, occupational physicians do not generally perform patch tests; this may mean an under-reporting of figures for occupational dermatitis associated with nickel exposure. With regard to the reporting systems, for future reference better definition of relevance of patch test results and for assessing causation would help improve the quality of the data collection.

Nickel sensitivity is common, ${ }^{22}$ usually being acquired through ear piercing, ${ }^{24}{ }^{25}$ and its role in occupational dermatitis is difficult to assess. Some authors believe that, in up to $25 \%$ of nickel allergic patients, nickel may be an important occupational allergen. ${ }^{152324}$ In the second part of the study, when reporters were asked to identify nickel allergy, whether coincidental or causational, in patients being reported with an OCD, nickel was judged by the reporting dermatologist to be an associated factor in the OCD in 36\% of cases. It is important to note that in most cases $(64 \%)$, nickel was not considered relevant despite the positive patch test. This was the case in occupations such as hairdressers and beauticians, nurses, food handlers, and floral arrangers in which other occupational agents were identified. In these instances, nickel was regarded as relevant to the causation of the dermatitis in fewer than $50 \%$ of those who had a positive patch test. On the other hand, although numbers are small, positive patch tests to nickel were felt to be relevant to OCD in people who handle coined money, including counter clerks, cashiers, cash and check out operators, in most of whom no other occupational factor was identified. In some jobs, such as sales assistant, the incidence of OCD with associated occupational exposure to nickel reported by dermatologists is low $(0.8 / 100000$ sales assistants), but this may represent a large number of cases because it is a common job. Conversely, for other work, the incidence is high (for example, 11.4/100 000 for beauticians), but the numbers may be lower because there are fewer employed.

In some groups, such as metal workers and electroplaters, it is agreed that occupational exposure can play a major part in the causation of dermatitis, ${ }^{75}$ although pre-existing nickel sensitivity has been shown in up to $88 \% .^{7}$ Exposure to irritants and wet work impair the barrier function of the skin and may make sensitisation to nickel more likely, with worsening of the dermatitis. ${ }^{7}$ In other workers such as hairdressers, cleaners, cashiers, shop assistants, and caterers, there is a potential for occupational nickel exposure, but workplace levels of exposure are difficult to quantify and the contribution of nickel to OCD hard to assess. Hairdressers do have contact with instruments that contain nickel, and these have been shown to release nickel on exposure to permanent wave fluids, ${ }^{26}$ but with the current use of stainless steel instruments, the nickel release will be less. In cleaning jobs, used water and cloths have been shown to contain appreciable amounts of nickel. ${ }^{10}$ Cashiers, counter clerks, and shop assistants handle nickel containing coins, ${ }^{14} 27$ and caterers and catering assistants come into contact with metal objects, some of which release nickel. ${ }^{28}$

\section{CONCLUSIONS}

In a small number of cases, reporters to EPIDERM considered that nickel exposure from coin handling, in the absence of other sensitising exposures, may be a contributor to OCD. European Union regulations ${ }^{29}{ }^{30}$ limit the amount of nickel

\begin{tabular}{|c|c|c|c|}
\hline Occupation & $\begin{array}{l}\text { Cases with a positive } \\
\text { allergic patch test to } \\
\text { nickel }\end{array}$ & $\begin{array}{l}\% \text { of cases in which } \\
\text { nickel was reported } \\
\text { as a suspected agent }\end{array}$ & $\begin{array}{l}\% \text { of cases in which } \\
\text { nickel was the sole } \\
\text { suspected agent }\end{array}$ \\
\hline Hairdressers & 77 & 19 & 4 \\
\hline Nurses & 40 & 25 & 10 \\
\hline Chefs/cooks & 27 & 26 & 11 \\
\hline Beauticians & 26 & 4 & 4 \\
\hline Cleaners/domestics & 19 & 79 & 63 \\
\hline Secretarial personnel & 17 & 94 & 94 \\
\hline Floral arrangers & 15 & 0 & 0 \\
\hline Packers/bottlers & 14 & 0 & 0 \\
\hline Catering assistants & 11 & 54 & 27 \\
\hline Counter clerks/cashiers & 7 & 100 & 86 \\
\hline Cash/checkout operators & 6 & 100 & 83 \\
\hline All occupations & 436 & 33 & 20 \\
\hline
\end{tabular}


released from products which come into prolonged contact with the skin (to $0.5 \mu \mathrm{g} / \mathrm{cm}^{2} /$ week), but some nickel sensitive patients may still react to this level of nickel exposure. ${ }^{29}$ In Denmark, these regulations began in 1991 and a decrease in the frequency of nickel allergy in children has already been shown. ${ }^{31}$ The relevance of occupational exposure to nickel to the causation of OCD will only be assessable when workplace measurements are possible and thresholds for reactivity defined.

\section{ACKNOWLEDGEMENTS}

We thank Dr M H Beck and Dr R J G Rycroft, who were instrumental in setting up the scheme, and Lisa Humphrys and Tracy Field, for their assistance in the EPIDERM office.

\section{Authors' affiliations}

K W Shum, D J Gawkrodger, Department of Dermatology, Royal Hallamshire Hospital, Glossop Road, Sheffield S10 2JF, UK J D Meyer, Y Chen, N Cherry, Centre for Occupational and Environmental Health, University of Manchester, Humanities Building, Manchester M13 9PL, UK

\section{REFERENCES}

1 Cherry NM, Meyer JD, Holt DL, et al. Surveillance of work-related diseases by occupational physicians in the UK: OPRA 1996-99. Occup Med 2000;50:265-73.

2 US Bureau of Labor Statistics. Nonfatal occupational illnesses by category of illness, private industry 1992-95. Washington, DC: US Department of Labor, 1997.

3 Kiec-Swierczynska M. Occupational allergic contact dermatitis in Lodz: 1990-1994. Occup Med 1996;46:205-8.

4 Wall LM, Gebauer KA. Occupational skin disease in Western Australia. Contact Dermatitis 1991;24:101-9.

5 Marcussen P. Ecological considerations on contact dermatitis. Ind Med 1960;17:65-8

6 Wall LM, Calnan CD. Occupational nickel dermatitis in the electroforming industry. Contact Dermatitis 1980;6:414-20.

7 Rystedt I, Fischer T. Relationship between nickel and cobalt sensitization in hard metal workers. Contact Dermatitis 1983:9:195-200.

8 Gaddoni G, Baldassari L, Francesconi E, et al. Contact dermatitis among decorators and enamellers in hand-made ceramic decorations. Contact Dermatitis 1993;28:127-8.

9 Fregert S. Occupational dermatitis in a 10-year material. Contact Dermatitis 1975;1:96-107.
10 Clemmensen OJ, Menné T, Kaaber K, et al. Exposure of nickel and the relevance of nickel sensitivity among hospital cleaners. Contact Dermatitis 1981;7:14-18.

11 Lammintausta K, Kalimo K, Havu VK. Occurrence of contact allergy and hand eczemas in hospital wet work. Contact Dermatitis 1982;8:84-90.

12 Acciai MC, Brusi C, Francalanci S, et al. Allergic contact dermatitis in caterers. Contact Dermatitis 1993;28:48.

13 Wahlberg JE. Nickel allergy in hairdressers. Contact Dermatitis 1981;7:358-9.

14 Gollhausen R, Ring J. Allergy to coined money: nickel contact dermatitis in cashiers. J Am Acad Dermatol 1991;25:365-9.

15 Shah M, Lewis FM, Gawkrodger DJ. Nickel as an occupational allergen: a survey of 368 nickel-sensitive subjects. Arch Dermatol 1998;134:1231-6.

16 Cherry N. Occupational disease. BMJ 1999;318:1397-9.

17 Cherry N, Meyer JD, Adisesh A, et al. Surveillance of occupational skin disease: EPIDERM and OPRA. Br J Dermatol 2000;142:1128-34.

18 Bourke J, Coulson I, English J. Guidelines for the care of contact dermatitis. Br J Dermatol 2001;145:877-85.

19 Office for National Statistics. Labour Force Survey, Winter 1996. London: The Stationery Office Publications Centre, 1997.

20 Office of Population Censuses and Surveys. Standard Occupational Classification. London: HMSO, 1990.

21 Uter W, Schnuch A, Geier J, et al. Epidemiology of contact dermatitis. The information network of departments of dermatology (IVDK) in Germany. Eur J Dermatol 1998;8:36-40.

22 Prystowsky SD, Allen AM, Smith RW, et al. Allergic contact hypersensitivity to nickel, neomycin, ethylenediamine and benzocaine. Arch Dermatol 1979;115:959-62.

23 McDonagh AJG, Wright AL, Cork MJ, et al. Nickel sensitivity: the influence of ear piercing and atopy. Br J Dermatol 1992;126:16-18.

24 Schubert H, Berova N, Czernielewski E, et al. Epidemiology of nickel allergy. Contact Dermatitis 1987;16:122-8.

25 Dawn G, Gupta G, Forsyth A. Epidemiology of nickel allergy from a Scottish tertiary referral centre over a 15 -year period [abstract]. Br J Dermatol 1999:141(suppl 55):95

26 Dahlquist I, Fregert S, Gruvbergr B. Release of nickel from plated utensils in permanent wave liquids. Contact Dermatitis 1979;5:52-3.

27 Van Ketel WG. Occupational contact with coins in nickel-allergic patients. Contact Dermatitis 1985;12:108-24.

28 Haudrechy $\mathbf{P}$, Foussereau J, Mantout B, et al. Nickel release from nickel-plated metals and stainless steels. Contact Dermatitis 1994;31:249-55.

29 Gawkrodger DJ. Nickel dermatitis: how much nickel is safe? Contact Dermatitis 1996;35:267-71

30 European Parliament and Council Directive 94/27/EC of 30 June 1994. Official Journal of the European Communities, 22.7.94, no. L188/1-2 (nickel).

31 Duus Johansen J, Menné T, Christophersen J, et al. Changes in the pattern of sensitisation to common contact allergens in Denmark between 1985-86 and 1997-98, with a special view to the effect of preventive strategies. Br J Dermatol 2000;142:490-5. 